\title{
Interactive Geovisualizations (iGE0): A New Approach to Teaching and Learning Physical Geography
}

\author{
Ryan HEINTZMAN1 \\ Arizona State University, Tempe, Arizona \\ USA
}

${ }^{1}$ Ph.D. student; Arizona State University, School of Geographical Sciences and Urban Planning, Tempe, Arizona, USA. ryan.heintzman [at] asu.edu, ORCID: 0000-0002-3126-6392

\begin{abstract}
Students completing an introductory physical geography course used an interactive geovisualizations (iGE0) lab exercise centered around lightning in northern Arizona to investigate atmospheric processes. This iGEO looks and plays like a conventional videogame where the student controls an avatar in a 3D environment. This iGEO was inspired by moving the introductory physical geography courses online due to the ongoing university closures to "on-the-ground classes" related the COVID-19 pandemic. The goal of an iGEO rests in increasing motivation and encouraging active, engaged learning for students, many of whom are taking the course for required college credit. Most students expressed positive experiences with the new iGEO; the determining factors related to this experience centered around enjoyment, usability, and simplicity of the game. There was also a difference in student experience based on student academic majors. Students of non-geographic or science backgrounds had a lower experience rating than those who did have a geographic or science background. Overall, students preferred the iGEO lab over traditional lab coursework. This research led to a refined iGEO lab for lightning in northern Arizona and it was made available to all interested faculty via a public website, along with three other iGEO-based labs.
\end{abstract}

\section{Keywords}

Geovisualization; Online Learning; Geography Pedagogy; Virtual Field Work; Gamification; North American Monsoon 
Geographic education in colleges and universities saw substantial shifts in teaching methods, technology use, and learning approaches over the past decade (Nellis, 2017; Jitmahantakul \& Chenrai, 2019; Artvinli, 2020). At the highereducation level, fluctuating class enrollment sizes accompanied with a movement towards online classes pose new challenges to both students and teachers. Impacts from the 2019 novel coronavirus had immediate impact for these learning methods at all levels of education and have pushed many into the realm of online learning. (Burgess \& Sievertsen, 2020; Sahu, 2020; Crawford. Butler-Henderson, Rudolph, \& Glowatz, 2020; Toquero, 2020). While online learning in higher education can be beneficial for both schools and students (Erickson, 2012), it can also lead to students feeling isolated, facing technical challenges, and becoming demoralized without contact of teachers or peers (Mazza \& Dimitrova, 2004). Fostering 21st Century skills is a keystone of geographic education in the classroom, it is a challenge to meaningfully translate those experiences into an online environment.

Many students with non-science majors enroll in science courses because they must fulfill a general education or major requirement (Smith. Gould, \& Jones, 2004). In the case of the physical geography lab at Arizona State University, this is a required lab science credit. These students may be unmotivated before the class even starts due to the mandatory nature of the course. A major factor for recruiting geography and geoscience students is through giving them positive course experiences, generally derived from an engaging and interactive introductory course (Stokes, Levine, \& Flessa, 2015). Interactive geovisualizations and gamification offer the necessary tools to address the challenges of student engagement, endearment, and retention encountered by traditional lecture, text, and assessment designed geography and geoscience courses

\section{Conceptual Framework}

\section{Gamification and Geovisualizations}

The development of games and geovisualizations for geography education provide students with a 'designed experience', where rather than absorbing the information from readings or lectures, students have first-hand experiences through being exposed to information (Squire, Giovanetto, Devane, Durga, 2005). Active learning methods have been shown to be a more effective method of instruction than passive, lecture or text-based learning as it engages students more directly in the material (Chi \& Wylie, 2014). Active learning methods in science can stem from different innovations in educating students. This can be using conceptual tasks with real-world problems, collaborative learning, new technologies, and inquiry-based project (Ruiz-Primo, Briggs, Iverson, Talbot, \& Shepard, 2011). Gamification often uses several pieces of active learning and engagement.

Gamification was first popularly defined as the use of game elements for increased engagement and motivation in non-game (i. e. marketing, education, etc.) environments (Deterding, Dixon, Khaled, \& Nacke, 2011). Ideally for education, effective gamification practice should motivate students both intrinsically and 
extrinsically; intrinsic motivation is found when students are doing something for the enjoyment of the activity, whereas extrinsic motivation is found in ideas such as the desire for good grades (Ryan \& Deci, 2000). Gamification can be used as an actual exercise or part of the course design through grading schemes. For instance, the grading system that the lab in this study utilizes is an accrual grading system, where students accrue points the more assignments they complete - this type of course design has seen successful application as a gamified course-assessment approach (Moll, 2020).

Actual games used in a course should be engaging on multiple levels: cognitive, social, and emotional (Lee \& Hammer, 2011). Incorporating efficient cognitive and emotional approaches requires that testing, practice, and failure; this should be framed as a learning experience rather than a mistake to be penalized immediately (Vleeshouwer, 2015). Socially, students can interact with other students on discussion boards and leaderboards (Machajewski, 2017), or take on different roleplaying identities, which places them in real world science occupations like climatologists (Wu \& Lee 2015) or geologists (Mead, Buxner, Bruce, Taylor, Semken, \& Anbar, 2019). Effective educational games should test the mental abilities of the student, allow them to collaborate or relate to others through roleplay, and bring them both entertainment and healthy challenge on the path to meaningful learning.

Online gamified courses typically lead to increases in student motivation (Dominguez, Saenz-de-Navarrete, de-Marcos, Fernández-Sanz, Pagés, \& MartínezHerráiz, 2013). This could be a result of the gamification being a novelty to students. As a result, it is important to not overlook the pedagogical framework of the class or exercise. It is important to realize that students experience gamified learning differently (Hamari, Koivisto, \& Sarsa, 2014). As a result, some researchers have called for a more diverse exploration of the effects of gamification, by looking at different techniques of gamification and their effectiveness with different groups of students (Dichev \& Dicheva, 2017).

Physical geography is centered around spatial awareness and spatial thinking. Spatial thinking allows for the interpretation of symmetry, orientation, and scale, as well as spatial and temporal changes (Schultz, Kerski, \& Patterson, 2008). Geovisualizations integrates the spatial awareness approaches from cartography and satellite imagery to provide a visual exploration tool for analysis and exploration (MacEachren, Brewer, \& Steiner, 2001). Many higher education students today are considered to be digital natives (Knight, 2009). With tools such as Google Earth, virtual reality, and interactive online games becoming more available, many students have responded positively to virtual geography education and gamification (Underwood, 2009; Pringle, 2013). Geography and geoscience games and geovisualizations have a wide range of applications, both in terms of interdisciplinary subjects and presentation. Topics range from topographic interpretation geovisualizations (Carbonell-Carrera \& Hess-Medler, 2019; Kubicek, Šašinka, Stachoň, Herman, Juř́ik, Urbánek, \& Chmelík, 2019) to climate change games (Jin \& Guo, 2009; Lee \& Hammer, 2011; Wu \& Lee, 2015; Wirehn, Opach, \& 
Neset, 2017). These games and geovisualizations provide effective tools for student motivation, engagement and learning.

\section{Fieldwork in Geography Education}

Fieldwork can be an influential, engaging, and enjoyable method of teaching and learning for teachers and students. Supervised learning in the field is driven by firsthand experience outside the classroom (Lonergan \& Andersen, 1988). There has been a long, active history of field work techniques used in geography education (Kent, Gilbertson, \& Hunt, 1997). With increasing and changing dynamics of student numbers for introductory geography classes, traditional in-person field work can pose a significant challenge (Leydon \& Turner, 2013). An increasingly relevant approach is to mitigate the challenges of high introductory student numbers and problems with accessibility through virtual field work.

Virtual fieldwork assists in spatial thinking. Virtual fieldwork tools and modules for geography courses and topics already exist in the form of applications such as Google Earth (Lamb \& Johnson 2010; Haslett, Skellern, Chilcott, \& Longman, 2011; Porter \& O'Connell, 2014; Treves, Viterbo, \& Hacklay, 2015) or in augmented reality (Bursztyn, Shelton, Walker, \& Pederson, 2017, Carbonell-Carrera \& Hess-Medler., 2019). Similar approaches have been made for geoscience courses, such as Habitable Worlds (Horodyskyj, Mead, Belinson, Buxner, Semken, \& Anbar, 2018) and Biobeyond (Anbar, Mead, Bratton, Horodyskyj, Hayes, Schonstein, et al., 2017); these virtual field trips allow students to listen to sounds, look around 360-degree images, and watch video lectures on site at locations like the Grand Canyon or Upheaval Dome in Moab, Utah, using the mentality of 'education through exploration'. Even fewer geographic education methods have used immersive virtual reality software (Sasinka, Stachoň, Sedlák, Chmelík, Herman, Kubíček, \& Šašinková, et al., 2019). Student learning and experiences using virtual education methods have been shown to meet or even exceed scores for students who visit sites in person (Ruberto, 2018), as well as drastically increase knowledge of the virtual field trip topic (Mead, Buxner, Bruce, Taylor., Semken, \& Anbar, 2019).

Virtual field trips may only be better suited to introductory laboratories, as students who answer higher-level questions have been shown to perform better when physically at a location as opposed to virtually (Stumpf, Douglass, \& Dorn, 2008). Virtual field trips also do not provide similar sensory experiences; some visual and audio integration is used in virtual field trips, but all lack smell and touch. Most virtual field trips are still not truly virtual because students cannot physically traverse or manipulate elements of the landscape (Cliffe, 2017). While virtual field work is generally seen as being equivalent or sometimes superior to in-person learning, some have called for more integrated approaches using lecture, real-world and virtual integrated approaches (Friess, Oliver, Quak, \& Lau, 2016), to combine positive aspects of all learning approaches. Students who face difficulties in virtual field education have also shown that a focus on student engagement may overlook 
the creation of effective teaching methods and pedagogy for virtual education (Dolphin, Dutchak, Karchewski, \& Cooper, 2019).

The lab exercise that uses the interactive lightning geovisualization discussed in this research contains a mixed form of traditional lecture material and new virtual approaches, as well as allows for students to traverse the landscape at their own discretion.

\section{Setting the Stage}

\section{Methods}

At Arizona State University, the introductory physical geography lecture (GPH111) and lab (GPH112) courses are taken together to meet a laboratory science requirement for graduation. In recent years, this course has seen a major shift from an on-the-ground delivery to an online delivery, as online education is becoming more available and class numbers are rising for these online courses. Traditionally, geography courses, both in-person or online were based around lab books, or lab practices; online assignments were difficult to recreate from in-class interactions. Recent course and assignment designs have taken a virtual focus using spatial software like Google Earth or interactive virtual field trips to better visualize concepts and provide students a level of autonomy and exploration in learning.

One major drawback of having students move into an online environment, specifically for the physical geography GPH112 lab science course, is the lack of several key aspects towards lab science and geographical learning. Students no longer have an ability to access and analyze information with hands-on interactive experiences, or to go outside and physically interact with a geography concept.

One solution to this predicament is the development of interactive geovisualizations (iGEOs), where students virtually traverse a digital elevation model (DEM) landscape that is superimposed with an interpretive data layer, such as rainfall, temperature, or in the case for this study, lightning. The goal of creating iGEOs for the GPH112 lab rests in providing students with the base lab components they miss from in-person courses, and to then promote an even greater amount of interactivity, engagement, and learning by taking students out into the field, to extreme or distant places that would be impossible for their in-person course, and have them analyze and interact with data virtually, as a scientist would in the field.

\section{The Interactive Geovisualization (iGE0)}

The first-generation geovisualization used for this research was a digital landscape map of the San Francisco Peaks, in northern Arizona (Figure 1). An extinct volcano, surrounding by volcanic fields of cinder cones and lava tubes, the peaks rise to over 3800 meters at its highest point, 1600 meters above the town of Flagstaff, northern Arizona, that is situated to the south of the mountain slopes. Many residents visit these mountains in both the summer and winter to hike, camp, bike, and ski, or visit the nearby Grand Canyon National Park. It is roughly a 2.5-hour drive from Phoenix to the mountain flanks, endearing itself as an approachable starting 
point as an iGEO destination that students may have some familiarity with, or may inspire them to visit after completion of the lab.

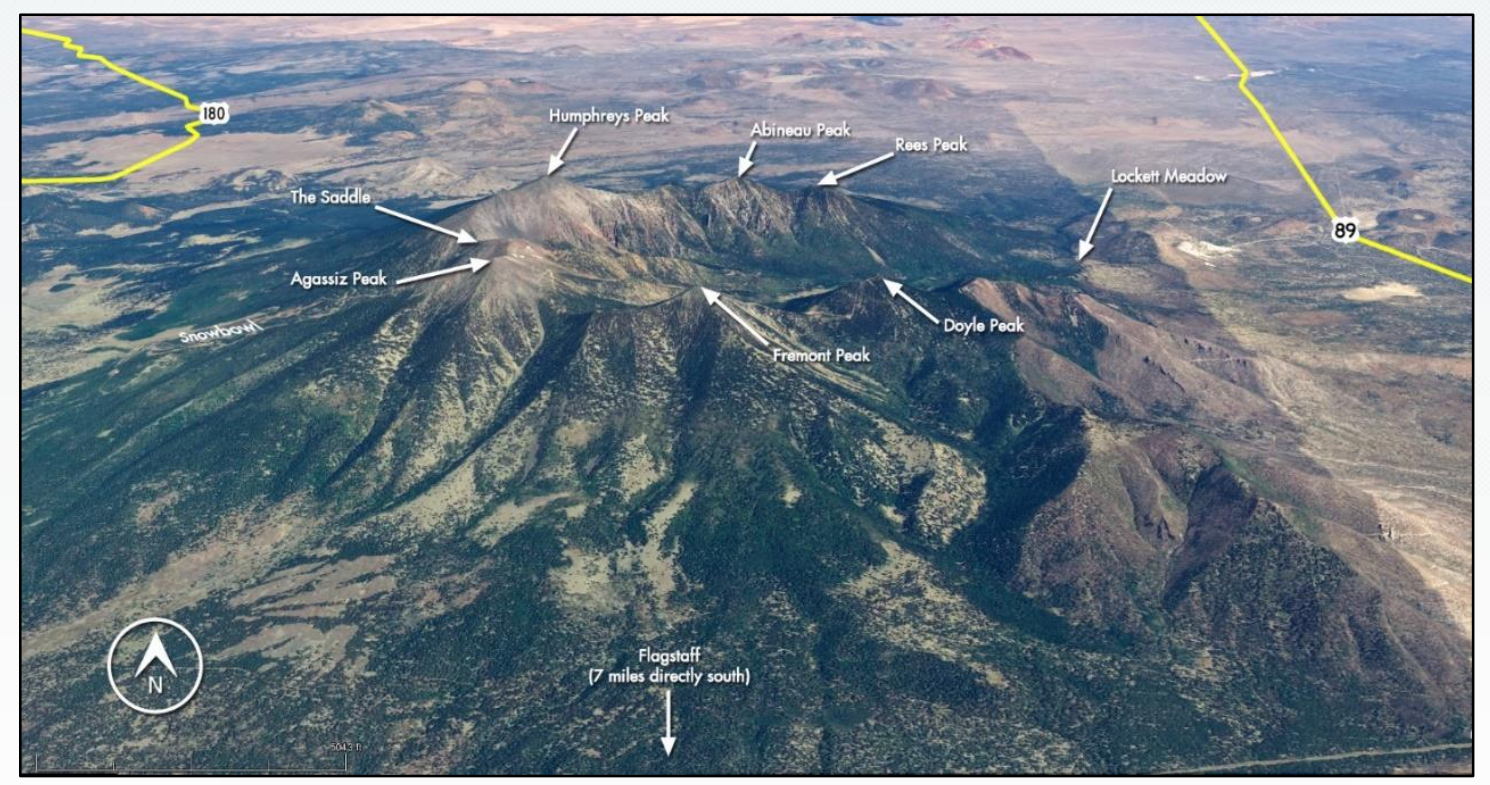

Figure 1. San Francisco Peaks, courtesy of the U.S. Forest Service (Public Domain Source: https://www.fs.usda.gov/Internet/FSE_MEDIA/stelprdb5428567.jpg )

The design of the iGEO was inspired by the popular block-based game, Minecraft, with the $30 \mathrm{~m}$ digital elevation model terrain elevation represented by colorful blocks (Figure 3). As such, the appearance of this iGEO would be familiar to many students. This style was also motivated by the concept of mature-age online students completing the assignment while interacting with their children and encouraging a shared experience. On top of the digital elevation blocks were simulated lightning strikes, representing lightning strikes during the summer monsoon. Northern Arizona and the San Francisco Peaks are beacons for summer thunderstorms during Arizona's monsoon season.

The iGEO gave players the option to type in specific latitude/longitude coordinates, or to "fast-travel" to unique locations in the region (Figure 2), such as Humphrey's Peak (the high point of the San Francisco Peaks), Snowbowl (the ski resort located on the western side of the mountain), or Sunset Crater (a cinder-cone volcano to the east of the San Francisco Peaks).

Students were encouraged to view the landscape using their mouse or touchpad and zoom in or out by scrolling. They would move around the environment with the WASD or arrow keys on their keyboards and jump with the SPACEBAR key. They were also given a game function of "Fast-Travel", where they could input latitude/longitude coordinates, and go to pre-set destinations. Students were able to view a readout of their block elevation and coordinates as well as track their movement across a DEM reference map.

The goal of the iGEO and the associated lab exercise was to encourage students to traverse the landscape, make observations of the lightning strikes at the given 
coordinate locations, and to demonstrate their understanding about the basic concepts of lightning, the North American Monsoon, and orographic influences on storm development.

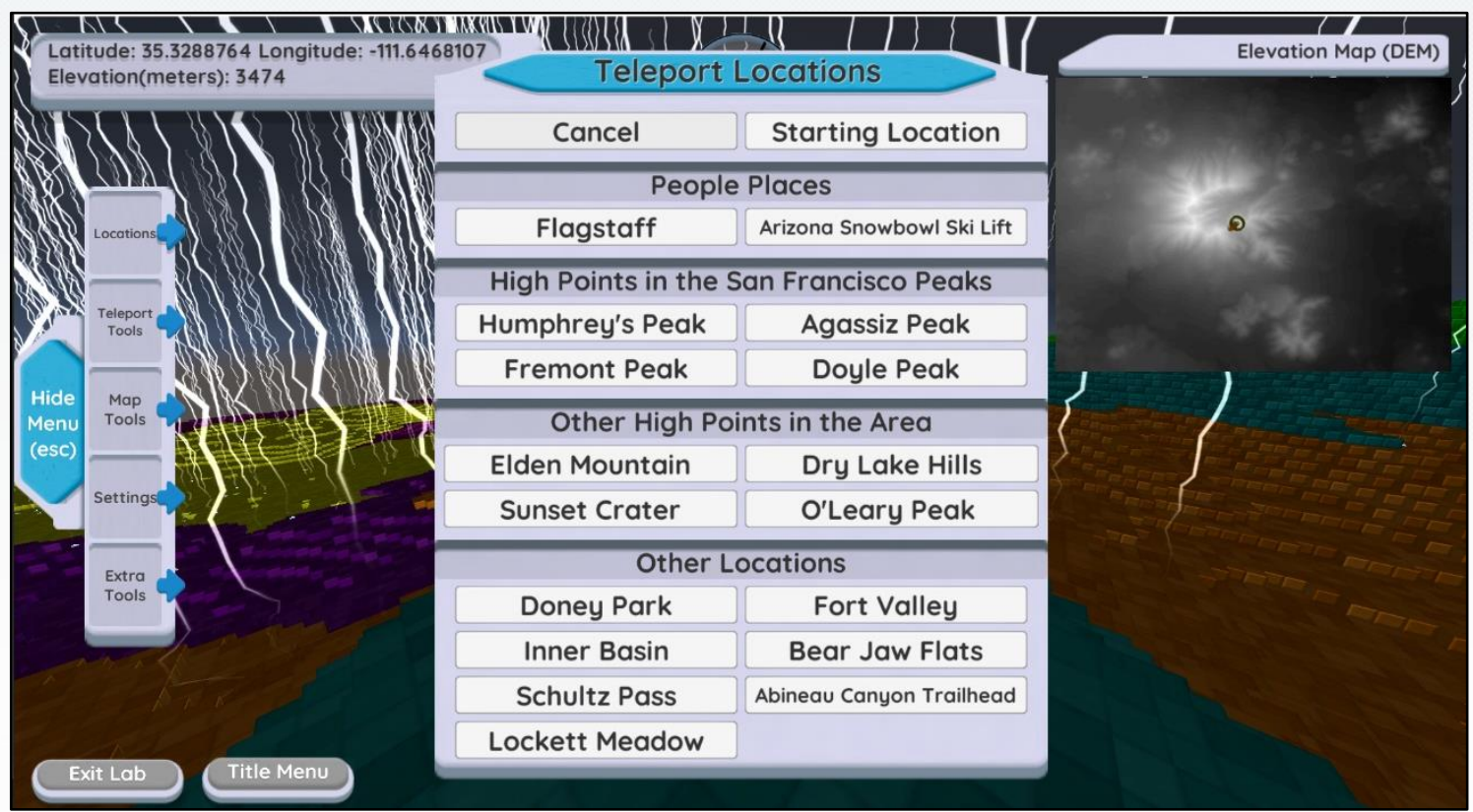

Figure 2. "Fast Travel" Teleport Locations

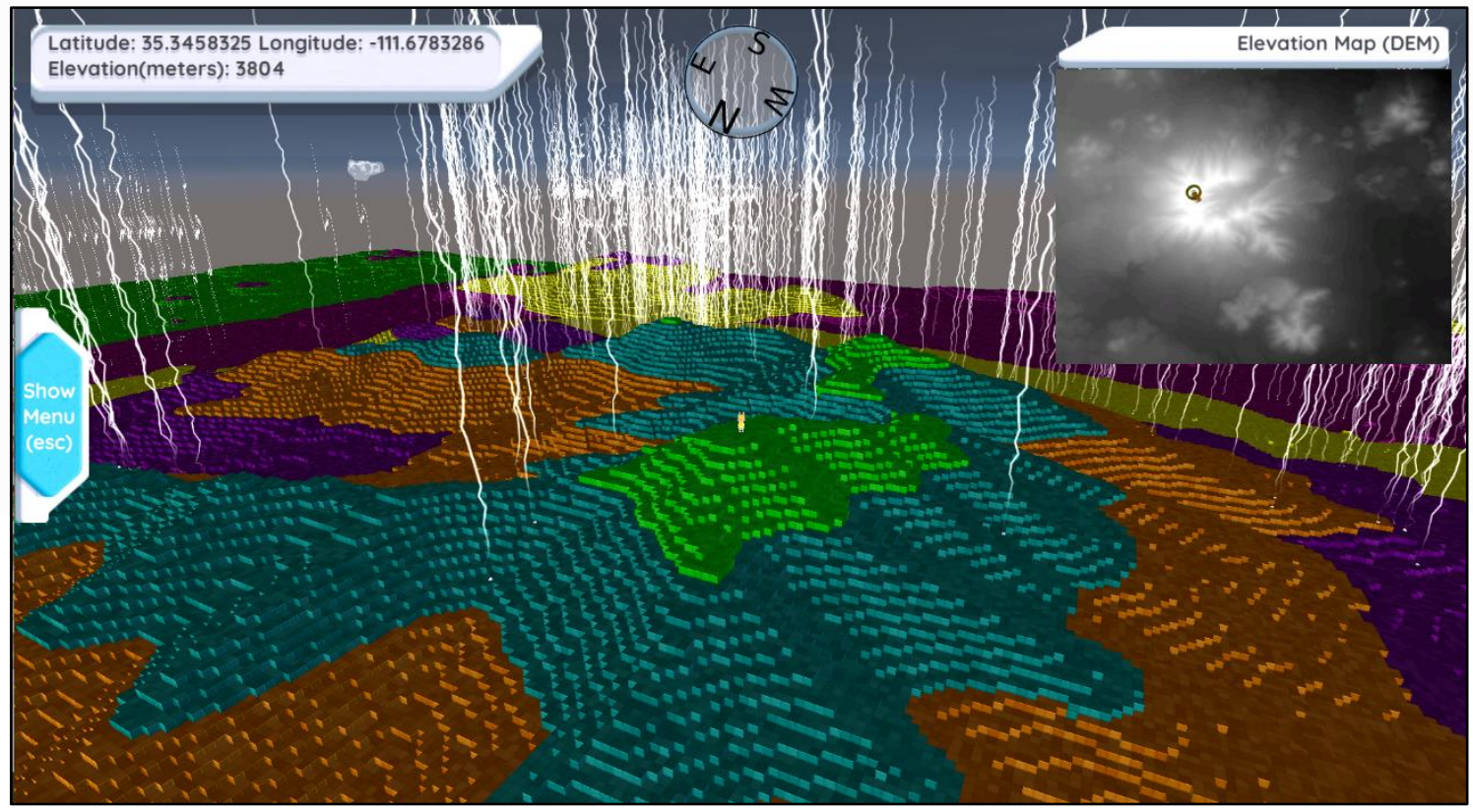

Figure 3. Northern Arizona Lightning iGEO design viewed from the top of Mt. Humphrey's

\section{The Lab}

The geovisualization lightning lab was broken into four sections (A, B, C, D), with each stage moving students towards a better understanding of the concepts and attempting to explain the distribution of lightning found in the game, based on the relationship between elevation and climate factors, specifically the North American Monsoon (Adams \& Comrie, 1997). The conceptual goal of this lab exercise is to 
develop student's deeper understanding of the atmospheric changes present in the North American monsoon. During July, August, and September low-level atmospheric winds shift towards the south, and the orographic influence of the San Francisco Peaks, lifting the now-humid air upward. In the iGEO, a heavy cluster of lightning was located along the southern flank of the San Francisco Peaks. While the dynamics of thunderstorm formation and direction are much more complicated than this lab portrays, it is conceptually appropriate for a lower-division assignment aimed at teaching the basic concepts of the relationship between climate and topography.

In Section A, an introductory stage, students simply make observations around the game at specific coordinates for what they saw, both in terms of the surrounding topography as well as the distribution of lightning. Given a table of locations to visit, students are tasked to write down observations. They then take a quiz to match different locations to their lightning and topographic descriptions.

Section B returns students to a traditional video lecture on the basics of lightning and the North American monsoon. This 20-minute online lecture gives students background information on lightning and the North American monsoon to help create connections with their previous observations. Students are then asked to test their knowledge with a quiz on the video lecture.

Section $\mathrm{C}$ is the heart of the lab, where students perform calculations to understand the changes in air temperature, dew point temperature, and winds over Flagstaff during the year, particularly with context to the North American monsoon and its important climatic presence in the southwest United States. Students also analyze radar imagery of thunderstorm tracks over the San Francisco Peaks and make basic calculations on storm velocity and trajectory. Lastly, students return to the geovisualization and determine which regions on the San Francisco Peaks were most frequently struck with lightning.

Section D involves students developing a synthesized four-paragraph response. In the first paragraph, students describe the changes in temperature, moisture and precipitation in Flagstaff, Arizona. In the second paragraph students explain thunderstorm development and the influence of orographic uplift. In the third paragraph students explain the North American monsoon, and how storm movement would be affected as it approached the peaks. In the final paragraph students explain the distribution of lightning in the iGEO.

\section{The Survey - Collection and Analysis}

Students were offered points towards their final grade if they gave feedback in the form of a survey. Alternative options were available for students who wished to accrue more points for their final grades but did not wish to participate in the survey. The survey was administered through Qualtrics and was accepted through ASU's institutional review board protocol. Questions in the survey were primarily Likert-scale questions centered around student agreement or disagreement. 
Cronbach's reliability coefficient had a high reliability, at .818. Understanding correlation between variables and questions focused on the Spearman's rho correlation, which is often used with ordinal scale, non-parametric data (Murray, 2013).

Table 1

Survey Questions

\begin{tabular}{lll}
\hline & Question & Response \\
\hline $\mathbf{1}$ & What is your area of study? & Open Response \\
\hline & & $\begin{array}{l}\text { Freshman } \\
\text { Sophomore } \\
\text { Junior } \\
\text { Senior }\end{array}$ \\
& What is your academic year? & SQ Credit \\
& \multirow{3}{*}{$\begin{array}{l}\text { Are you taking this lab class to complete a required SQ } \\
\text { credit, because of prior interest, or both? }\end{array}$} & $\begin{array}{l}\text { Prior Interest } \\
\text { Both }\end{array}$ \\
\hline
\end{tabular}

A great deal $(25+$ hours a week)

$4 \quad$ Do you play video games?

A lot (15-25 hours a week)

Sometimes (5-15 hours a week)

A little (1-5 hours a week)

Not at all (0 hours a week)

5 Did you have friends/family join you when using the lightning geovisualization?

Yes / No

A great deal (over 25

Did you spend time exploring the lightning/topography

6 around the San Francisco Peaks, independent from the minutes)

A lot (15-25 minutes)

lab questions?

Somewhat (5-15 minutes)

A little (1-5 minutes)

Not at all

\begin{tabular}{|c|c|c|}
\hline 7 & I would describe myself as a visual learner. & \multirow{11}{*}{$\begin{array}{l}\text { Strongly Agree } \\
\text { Agree } \\
\text { Neither } \\
\text { Disagree } \\
\text { Strongly Disagree }\end{array}$} \\
\hline 8 & I enjoyed using the lightning geovisualization. & \\
\hline 9 & $\begin{array}{l}\text { I would rather have used images/text/tables instead of } \\
\text { the geovisualization. }\end{array}$ & \\
\hline 10 & I found the geovisualization simple to use. & \\
\hline 11 & I had issues with the geovisualization software. & \\
\hline 12 & I think the geovisualization could be improved. & \\
\hline 13 & $\begin{array}{l}\text { The geovisualization helped me to better understand } \\
\text { the other sections in the lightning lab. }\end{array}$ & \\
\hline 14 & I would like to use geovisualizations in other lab topics. & \\
\hline 15 & $\begin{array}{l}\text { The geovisualization increased my general interest in } \\
\text { geography. }\end{array}$ & \\
\hline 16 & $\begin{array}{l}\text { The geovisualization increased my interest in } \\
\text { lightning/topography. }\end{array}$ & \\
\hline 17 & $\begin{array}{l}\text { The geovisualization made me want to visit } \\
\text { Flagstaff/San Francisco Peaks in person. }\end{array}$ & \\
\hline
\end{tabular}




\section{Results}

\section{Quantitative Survey Feedback}

From the 64 students surveyed, the consensus was the lightning geovisualization was a positive experience (Figure 4). Of the 64 surveyed students $71.9 \%$ claimed that they enjoyed using the geovisualization and slightly over three-quarters of students $(77.8 \%)$ agreed that the lightning geovisualization helped them to better understand other sections of the lab exercise $(14.3 \%$ were neutral while $7.9 \%$ disagreed). Interest in both geography and lightning increased (60.9\% Agree; 9.4\% Disagree; 67.2\% Agree; 7.8\% Disagree respectively).

Nearly all surveyed students (95.3\%), described themselves as visual learners, while almost half of surveyed students play any video games (43.8\%). A small group $(15.6 \%)$ of students had friends/family join them when playing with the lightning geovisualization. Most students (81.2\%) explored the game landscape for at least a few minutes, outside of the required location questions required by the assignment and many students expressed interest in visiting Flagstaff and the San Francisco Peaks in person (65.6\% Agree; 7.9\% Disagree).

Compared to traditional learning methods (such as images/tables/text) found in the other lab exercise, over half of students said they preferred the geovisualization approach (57.9\%). Most students (75\%) expressed interest in the incorporation of geovisualizations for other lab topics, however, $60.9 \%$ of students agreed that the geovisualizations could be improved.

\section{Spearman's Rho Correlation}

Spearman's Rho correlation statistics were used to better understand relationships between non-parametric question results of the Likert-scale data. Strong correlation (.654) exists between student enjoyment and increased interest in geography. Strong correlation (.557) exists between student enjoyment and preference for the geovisualization over traditional learning methods.

Strong correlation (.510) exists between the perceived usefulness of the geovisualization and the preference for using the geovisualization over traditional learning methods. Moderate correlation (.484) exists between perceived simplicity and preference for the geovisualization over traditional teaching methods. Moderate negative correlation (-.401) exists between students who encountered problems and those who had an increased interest in geography. Moderate correlation (.385) exists between students who play video games and those who found the geovisualization simple to use. 


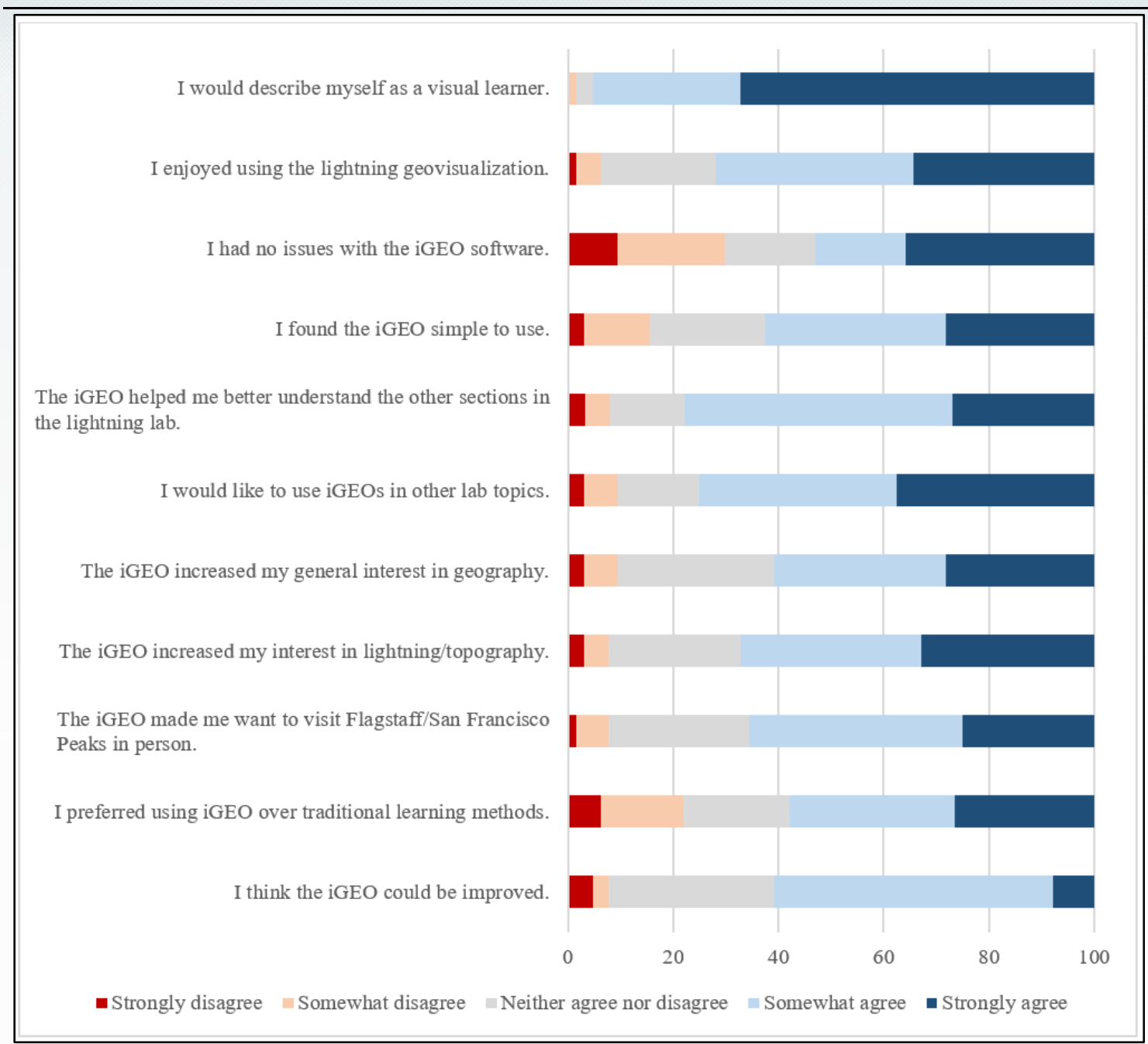

Figure 4. Student survey question responses (percentage). Statement responses are denoted by the following colors: dark red: strongly disagree; light red; somewhat disagree; gray: neither agree nor disagree; light blue: somewhat agree; dark blue: strongly agree

\section{Experience by Major Background and Academic Year}

Nine questions from the survey $(\mathrm{Q} 8, \mathrm{Q} 9, \mathrm{Q} 10, \mathrm{Q} 11, \mathrm{Q} 13, \mathrm{Q} 14, \mathrm{Q} 15, \mathrm{Q} 16, \mathrm{Q} 17)$ were used to create a student experience metric to better compare experiences by major background and academic year. Due to the nature of the data being ordinal, this experience metric was found by taking the median value for each individual student. This allowed for analysis by academic year (Figure 5) and academic major (Figure 6). Students with a higher median response were deemed to have a more positive course experience.

Two of the questions were altered to be used in this experience metric to better align with positive and negative responses. Question X was altered from "I had issues with the geovisualization software" to "I had no issues with the geovisualization software". Question X was changed from "I would rather have used images/text/tables instead of the geovisualization" was changed to "I preferred using the geovisualization over images/text/tables". 
Heintzman, R. (2020). Interactive Geovisualizations (iGEO): A New Approach to Teaching and...

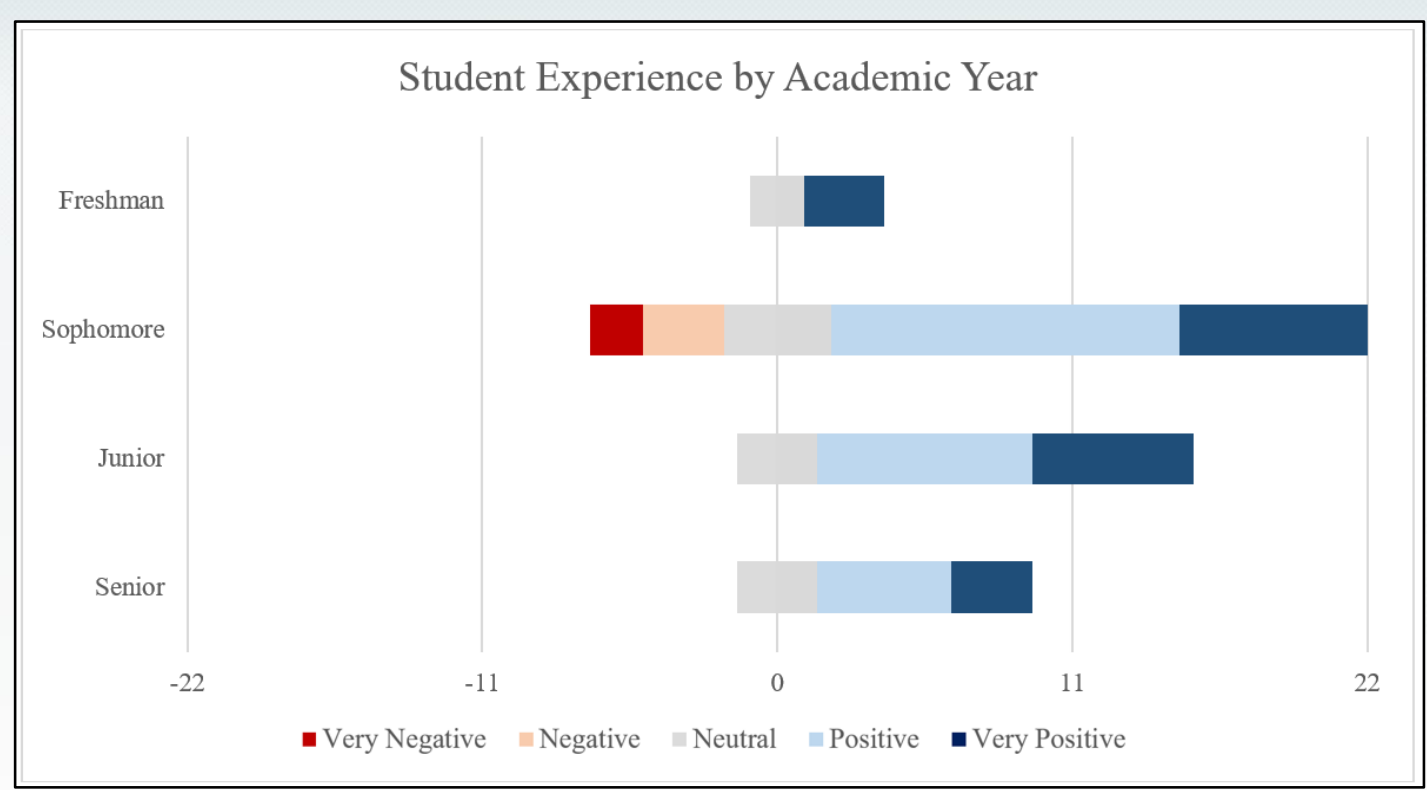

Figure 5. Student Experience by academic year. Student experiences are denoted by the following colors: dark red: very negative; light red; negative; gray: neutral; light blue: positive; dark blue: very positive

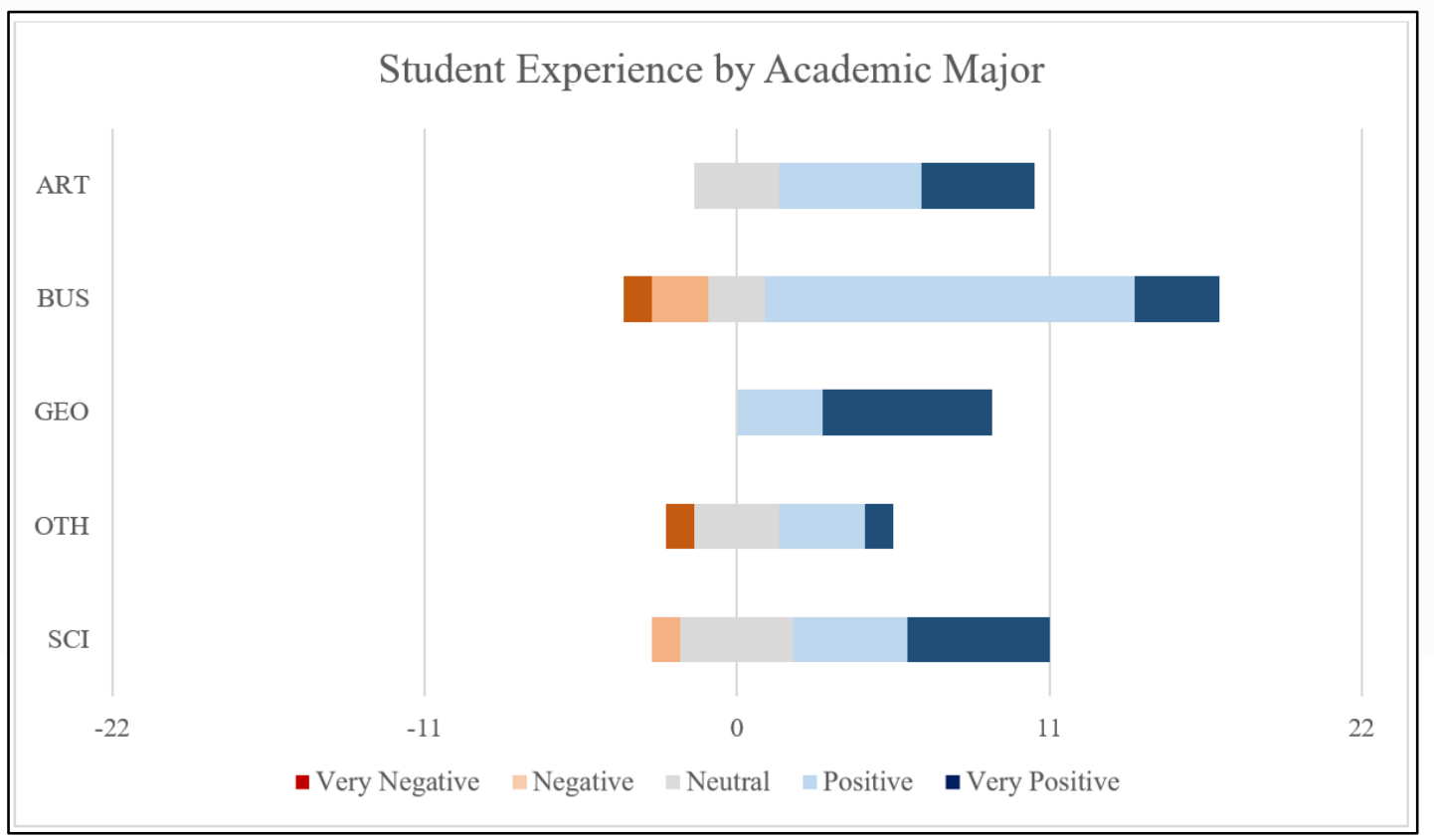

Figure 6. Student Experience by Academic Major. Student experiences are denoted by the following colors: dark red: very negative; light red; negative; gray: neutral; light blue: positive; dark blue: very positive

Mean response experience variables were calculated for academic year and major. Freshman and Junior academic majors had the most positive experience (1.80 and 1.82 respectively), while Senior students and especially Sophomore students were more mixed in their experiences ( 2.0 and 2.3 respectively).

Geography majors had statements that exhibited an overwhelmingly positive experience (1.6), followed by Arts (2.1), Science (2.3), Business (2.4), and 
Other/Undecided (2.6). The closer to the value of 1 , means that the student more strongly agreed with positive experience questions, while closer to 3 is more of a neutral experience, and closer to 5 is a negative experience, strongly disagreeing with the experience statement.

Geography majors had generally better experiences with the lightning geovisualization and much less likely than other majors to have preferred traditional learning methods over the geovisualization lab. Arts majors typically had positive experiences, while science majors were of slightly more mixed opinions. Compared to Business or Other/Undeclared majors, Geography majors were often a magnitude of certainty different. Business and Other/Undeclared majors were almost always less positive (towards 5) about the iGEO lab.

\section{Qualitative Data}

Along with the survey, students were asked to give written feedback about geovisualization lab for lightning which gives the lab developers valuable feedback as well as insights into student experiences that could not be extracted from the Likert-scale survey. A small number of responses are displayed below, showcasing the most common themes for positive and critical written feedback (Table 2).

Table 2

Student Written Feedback

\begin{tabular}{|c|c|}
\hline Positive Feedback & Critical Feedback \\
\hline $\begin{array}{l}\text { "This was by far the most creative and fun } \\
\text { tool I've ever used in a class. It was very } \\
\text { simplistic but got the job done at the same } \\
\text { time. As a meteorology fanatic this program } \\
\text { really grabbed my interest." }\end{array}$ & $\begin{array}{l}\text { "The lightning lab was a little confusing for } \\
\text { me mainly because I am not good at using } \\
\text { computer programs. I would have preferred } \\
\text { a reading assignment, and questions to } \\
\text { answer." }\end{array}$ \\
\hline $\begin{array}{l}\text { "The lightning lab is amazingly fun and } \\
\text { informative. Science is an interesting topic } \\
\text { but the process of studying it can be so } \\
\text { boring -the advantage technology used for } \\
\text { the visualization in this class turned the } \\
\text { boring portion of studying science into a } \\
\text { spectacular, and again, an amazingly fun } \\
\text { game." }\end{array}$ & $\begin{array}{l}\text { "While I understand that everyone learns } \\
\text { differently, this is not a format I would ever } \\
\text { want to be forced into. I don't see the benefit } \\
\text { to applying this approach instead of sticking } \\
\text { to a neatly-written/organized PDF file of } \\
\text { facts and figures." }\end{array}$ \\
\hline
\end{tabular}

"I really enjoyed the lightning lab, and so did my daughter! Thanks to you, she thinks college is so cool!"

"I thought it was extremely neat. I have never experienced such a lab before. Being able to look around and see the lightning was really cool to experience."
"I could have learned just as much from a series of photographs or something, but the amount of time I spent wrestling with the geovisualization tools didn't learn to me really learning much or having a better understanding of lightning." 


\section{Discussion}

The objective of this study rests in understanding the student experience with a new interactive geovisualization for lightning set in northern Arizona as part of an online introductory physical geography lab course. Inspired by the long history of field work education in geography (Kent et al., 1997) and the challenges faced by fluctuating enrollment and teaching medium (Leydon \& Turner, 2013), this iGEO was designed to allow students to become virtual researchers. The ultimate goal was for students to understand storm formation and lightning distribution in the mountainous terrain of northern Arizona. Based on the survey results, students responded positively to the interactive geovisualization about lightning as a part of a physical geography lab exercise to teach climate variability. These positive responses were shaped by academic year and majors, as well as personal experiences with the iGEO lab exercise. As gamification in education has grown, some have called for a diversified exploration of student experience, to better understand the pedagogy and individual student experience (Dichev \& Dicheva, 2017). This preliminary research was not aimed specifically at analyzing student performance; that has been shown to be true in many other iterations of virtual learning and field work. Instead, this research was more focused on understanding student backgrounds and influences that may have shaped their experiences with the iGEO lab.

One reason for development of this iGEO lab was due to the understanding that many incoming students to universities are technology literate and oriented toward visual learning (Knight, 2009). Over 95\% of students in the survey described themselves as visual learners, and research into virtual gamification has generally been favorable in terms of motivation, experience, and student learning (Underwood, 2009; Ruberto, 2018; Mead et al., 2019). While there are many iterations of learning through virtual field trips using applications like Google Earth (Lamb \& Johnson, 2010; Haslett et al., 2011; Porter \& O'Connell, 2014; Treves et al., 2015), the goal of this lab was to provide the so-called 'digital natives' with something more interactive. Just over half of students preferred to use an iGEO over traditional online learning methods. This was a surprise, and one that should be higher in future iterations of the lab. The reasons for the low percentage are multifaceted. One reason could be due to the influence of students encountering problems with the software. Just under two-thirds (29.7\%) of students claimed to encounter problems with the iGEO, while $15.6 \%$ of students found the software difficult to use. Another possible reason behind this number is because of the different structure of the lab exercise for lightning compared to the rest of the lab exercises. This may have resulted in the lab design itself being unfamiliar.

Student feedback on the iGEO was based around several factors. When looking specifically at student's preference to using the iGEO over the traditional learning methods (Q9) used in the rest of the class, several question themes appeared, those being enjoyment, usefulness, and simplicity (associated with Q8, Q10, Q13 
respectively). Students were more likely to prefer the iGEO method of learning if they found iGEO enjoying, if they found that it was helpful to their understanding to the lab questions, and if they could navigate the game easily and efficiently. Students who rated the iGEO as simple to use were more likely to have experience with video games as well.

Students in this course have wide ranging academic backgrounds, and as such have unique experiences with iGEO education. Many students, often during their Sophomore year, enroll in lab science courses because of the general education or major requirement (Smith et al., 2004). Roughly two-thirds of students who participated in the iGEO survey were from majors outside of science or geography majors, and nearly half were Sophomores. This distribution of backgrounds can pose a challenge to both students and instructors with regards to experiences and motivations towards the course. Second year students had a greater variation in lab enjoyment than other academic years. This may be due to the mandatory nature of the course, in which many students take their required courses for graduation in their sophomore years. With regards to academic majors, geography students had an overwhelmingly positive experience with the geovisualization lab, while students with less background in geographic concepts described their experience as less positive. Business majors and undecided majors, which comprised nearly half of the course, typically had the lowest rated experience with the geovisualization compared to science, arts, and geography majors. While students who are undeclared or business majors may have less experience with geography and the information taught in the geovisualization lab, it will be necessary going forward with these geovisualizations to be more inclusive and understand other factors that may have influenced the student's responses.

Education using visually oriented learning should be structured in a way that is accessible to every student. It cannot be based around increasing motivation and the assumption that all students will be immediately fluent in iGEO education. Focusing only on student engagement can overlook the development of effective pedagogy in virtual education (Dolphin, Dutchak, Karchewski, \& Cooper, 2019). Effective teaching methods and pedagogy are imperative in the development of new iGEO labs. Online education has problems with isolation, technology issues, and lack of instruction (Mazza \& Dimitrova, 2004). Just under one-third (29.7\%) of students claimed to encounter problems with the iGEO, while $15.6 \%$ of students found the software difficult to use. In order to meaningfully translate classroom education virtually using iGEOs, there must be willing and motivated course designers and instructors on the other side who are creating tutorials, providing effective feedback, and answering questions. While this is may be demanding compared to traditional pedagogical methods, great potential is available to engage students with the geographical concepts from all ages and academic backgrounds. 


\section{Limitations}

A significant limitation to this study is whether or not the positive engagement with this study lies within the novelty of gamification and new lab structure compared to the normal lab exercises. As stated previously, some students also had technical issues accessing certain portions of the iGEO because it was in preliminary stages for the development of this lab. This research also did not go into depth about many other factors that could have influenced student's perceptions of the iGEO, such as demographics, game accessibility and complications, etc. After the completion of this research, the physical geography lab at Arizona State University has been designed wholly around these iGEO labs, and greater study is currently being conducted to better understand this method of learning.

\section{Conclusion}

Geography education has encountered considerable changes over the past decade: students come from disparate experiences and academic backgrounds; class sizes are fluctuating; and there has been a movement towards online education. More recently, the outbreak of Covid-19 has impacted both students and instructors alike, pushing many into the realm of online learning. These factors have led to the creation of the lightning iGEO, and others in development.

This research shows that interactive geovisualizations are a capable and engaging learning tool for students of introductory physical geography courses, however, consideration of study background is necessary for all students to have positive, engaged learning experiences. A major goal of this iGEO lab for lightning is to create a unique and interactive learning experience which provides students of all study backgrounds a new way to explore a landscape and learn the concepts of geography. This lab structure will be explored further with a current introductory physical geography class incorporating only geovisualization centered labs. More indepth analysis on student background and their experience with the geovisualizations as part of a geography lab will be performed, increasing the understanding of inclusivity for iGEO learning.

This research led to a revision of the northern Arizona lightning lab and iGEO. The revised lab and the iGEO are made freely available to all interested faculty at this public website: http://www.public.asu.edu/ atrid/111_OnlineGeovisualization Labs.html

In addition to the new version of the lightning lab, there are labs developed for with interactive geovisualizations of the Grand Canyon and the Big Island of Hawai'i.

\section{Acknowledgement}

The author wishes to thank Prof. Ronald Dorn for comments on earlier versions of this paper, and for countless learning and research opportunities. 


\section{References}

Adams, D.K. \& Comrie, A.C., 1997. The north American monsoon. Bulletin of the American Meteorological Society, 78(10), 2197-2214.

Anbar, A. D., Mead, C., Bratton, D., Horodyskyj, L., Hayes, J., Schonstein, D., Watt, S., Watt, K., Ben-Naim, D., \& Leon, A. (2017). Demonstrating the Value of Education Through Exploration as a Theory of Digital Design. AGU Fall Meeting Abstracts, 2017, ED41B0275.

Artvinli, E. (2020). From the editor: special issue on the UCEK/ICGE-2019. Review of International Geographical Education, 10, 8-13.

Burgess, S., \& Sievertsen, H. H. (2020). Schools, skills, and learning: The impact of COVID-19 on education. VoxEu. org, 1.

Bursztyn, N., Shelton, B., Walker, A., \& Pederson, J. (2017). Increasing Undergraduate Interest to Learn Geoscience with GPS-based Augmented Reality Field Trips on Students' Own Smartphones. GSA Today, 27(5), 4-10.

Carbonell-Carrera, C., \& Hess-Medler, S. (2019). Interactive Visualization Software to Improve Relief Interpretation Skills: Spatial Data Infrastructure Geoportal versus Augmented Reality. The Professional Geographer, 0(0), 1-13.

Chi, M. T. H., \& Wylie, R. (2014). The ICAP Framework: Linking Cognitive Engagement to Active Learning Outcomes. Educational Psychologist, 49(4), 219-243.

Cliffe, A. D. (2017). A review of the benefits and drawbacks to virtual field guides in today's Geoscience higher education environment. International Journal of Educational Technology in Higher Education, 14(1), 28.

Crawford, J., Butler-Henderson, K., Rudolph, J., Glowatz, M. (2020). COVID-19: 20 Countries' Higher Education Intra-Period Digital Pedagogy Responses. Journal of Applied Learning \& Teaching, 3(1), 1-20.

Deterding, S., Dixon, D., Khaled, R., \& Nacke, L. (2011). From game design elements to gamefulness: Defining "gamification." Proceedings of the 15th International Academic MindTrek Conference: Envisioning Future Media Environments, 9-15.

Dichev, C., \& Dicheva, D. (2017). Gamifying education: what is known, what is believed and what remains uncertain: a critical review. International Journal of Educational Technology in Higher Education, 14(1), 9.

Dolphin, G., Dutchak, A., Karchewski, B., \& Cooper, J. (2019). Virtual field experiences in introductory geology: Addressing a capacity problem, but finding a pedagogical one. Journal of Geoscience Education, 67(2), 114-130.

Domínguez, A., Saenz-de-Navarrete, J., de-Marcos, L., Fernández-Sanz, L., Pagés, C., \& Martínez-Herráiz, J.-J. (2013). Gamifying learning experiences: Practical implications and outcomes. Computers \& Education, 63, 380-392.

Erickson, A.S.G., Noonan, P.M. and McCall, Z., 2012. Effectiveness of online professional development for rural special educators. Rural Special Education Quarterly, 31(1), 2232.

Friess, D. A., Oliver, G. J. H., Quak, M. S. Y., \& Lau, A. Y. A. (2016). Incorporating "virtual" and "real world" field trips into introductory geography modules. Journal of Geography in Higher Education, 40(4), 546-564. 
Hamari, J., Koivisto, J., \& Sarsa, H. (2014). Does Gamification Work? -- A Literature Review of Empirical Studies on Gamification. 2014 47th Hawaii International Conference on System Sciences (HICSS), 3025-3034.

Haslett, S. K., Skellern, A., Chilcott, M., \& Longman, D. (2011). Climate change education through a blended learning Google Earth exercise. Pedagogy of Climate Change, Higher Education Academy, York, 112-127.

Horodyskyj, L. B., Mead, C., Belinson, Z., Buxner, S., Semken, S., \& Anbar, A. D. (2018). Habitable Worlds: Delivering on the Promises of Online Education. Astrobiology, 18(1), 86-99.

Jin, H., \& Guo, D. (2009). Understanding Climate Change Patterns with Multivariate Geovisualization. 2009 IEEE International Conference on Data Mining Workshops (ICDMW), 217-222.

Jitmahantakul, S., \& Chenrai, P. (2019). Applying Virtual Reality Technology to Geoscience Classrooms. Review of International Geographical Education, 9(3), 577-590.

Kent, M., Gilbertson, D. D., \& Hunt, C. 0. (1997). Fieldwork in geography teaching: A critical review of the literature and approaches. Journal of geography in higher education, $21(3), 313-332$.

Knight, Y. (2009). Talkin' 'bout my generation: a brief introduction to generational theory. Planet, 21(1), 13-15.

Kubíček, P., Šašinka, Č., Stachoň, Z., Herman, L., Juř́k, V., Urbánek, T., \& Chmelík, J. (2019). Identification of altitude profiles in 3D geovisualizations: the role of interaction and spatial abilities. International Journal of Digital Earth, 12(2), 156-172.

Lamb, A., \& Johnson, L. (2010). Virtual Expeditions: Google Earth, GIS, and Geovisualization Technologies in Teaching and Learning. Teacher Librarian, 37(3), 81-85.

Lee, J., \& Hammer, J. (2011). Gamification in Education: What, How, Why Bother? Academic Exchange Quarterly, 15, 1-5.

Leydon, J., \& Turner, S. (2013). The Challenges and Rewards of Introducing Field Trips Into a Large Introductory Geography Class. Journal of Geography, 112(6), 248-261.

Lonergan, N., \& Andresen, L. W. (1988). Field-Based Education: Some Theoretical Considerations. Higher Education Research \& Development, 7(1), 63-77.

MacEachren, A. M., Brewer, I., \& Steiner, E. (2001). Geovisualization to mediate collaborative work: Tools to support different-place knowledge construction and decision-making. In Proceedings of the 20th International Cartographic Conference, 6-10.

Machajewski, S. (2017). Gamification Strategies in a Hybrid Exemplary College Course. International Journal of Educational Technology, 4, 1-16.

Mazza, R., \& Dimitrova, V. (2004, May). Visualising student tracking data to support instructors in web-based distance education. In Proceedings of the 13th international World Wide Web conference on Alternate track papers \& posters, 154-161.

Mead, C., Buxner, S., Bruce, G., Taylor, W., Semken, S., \& Anbar, A. D. (2019). Immersive, interactive virtual field trips promote science learning. Journal of Geoscience Education, 67(2), 131-142.

Moll, H. L. (2020). Leveling Up Grades: A Pilot Study of Student Motivation when an EntryLevel Geography Course Uses Point-Accrual Class Assessment. Yearbook of the Association of Pacific Coast Geographers, 82, 145-159. 
Murray, Jacqueline. (2013). Likert data: what to use, parametric or non-parametric?. International Journal of Business and Social Science, 4(11), 258-264.

Nellis, M. D. (2017). Higher Education: implications for geography learning. Journal of Geography in Higher Education, 41(2), 155-165.

Porter, J. C., \& O'Connell, S. (2014). Encounter Physical Geography: Interactive Explorations of Earth; Using Google Earth. Pearson.

Pringle, J. K. (2013). Educational environmental geoscience e-gaming to provide stimulating and effective learning. Planet, 27(1), 21-28.

Ruberto, T. J. (2018). Implications of Learning Outcomes of In-person and Virtual Fieldbased Geoscience Instruction at Grand Canyon National Park. Doctoral dissertation, Arizona State University.

Ruiz-Primo, M. A., Briggs, D., Iverson, H., Talbot, R., \& Shepard, L. A. (2011). Impact of undergraduate science course innovations on learning. Science, 331(6022), 12691270.

Ryan, R. M., \& Deci, E. L. (2000). Intrinsic and Extrinsic Motivations: Classic Definitions and New Directions. Contemporary Educational Psychology, 25(1), 54-67.

Sahu, P. (2020). Closure of Universities Due to Coronavirus Disease 2019 (COVID-19): Impact on Education and Mental Health of Students and Academic Staff. Cureus, 12(4).

Šašinka, Č., Stachoň, Z., Sedlák, M., Chmelík, J., Herman, L., Kubíček, P., Šašinková, A., Doležal, M., Tejkl, H., Urbánek, T., Svatoňová, H., Ugwitz, P., \& Juřík, V. (2019). Collaborative Immersive Virtual Environments for Education in Geography. ISPRS International Journal of Geo-Information, 8(1), 3.

Schultz, R. B., Kerski, J. J., \& Patterson, Todd C. (2008). The Use of Virtual Globes as a Spatial Teaching Tool with Suggestions for Metadata Standards. Journal of Geography, 107(1), 27-34.

Smith, W. S., Gould, S. M., \& Jones, J. A. (2004). National Science Teachers Association Starting the Semester at Odds: Educators' Versus Students' Reasons for Studying Science. Journal of College Science Teaching, 34(3).

Stokes, P. J., Levine, R., \& Flessa, K. W. (2015). Choosing the Geoscience Major: Important Factors, Race/Ethnicity, and Gender. Journal of Geoscience Education, 63(3), 250-263.

Stumpf, R. J., Douglass, J., \& Dorn, R. I. (2008). Learning Desert Geomorphology Virtually versus in the Field. Journal of Geography in Higher Education, 32(3), 387-399.

Toquero, C. M. (2020). Challenges and Opportunities for Higher Education amid the COVID19 Pandemic: The Philippine Context. Pedagogical Research, 5(4).

Treves, R., Viterbo, P., \& Haklay, M. (Muki). (2015). Footprints in the sky: using student track logs from a "bird's eye view" virtual field trip to enhance learning. Journal of Geography in Higher Education, 39(1), 97-110.

Underwood, J.D. (2009). The impact of digital technology. Coventry, BECTA.

Vleeshouwer, J. J. (2015). Gamification in higher education: factors influencing the usage intensity of a gamified E-learning application. Master thesis, University of Twente.

Wiréhn, L., Opach, T., \& Neset, T.-S. (2017). Assessing agricultural vulnerability to climate change in the Nordic countries - an interactive geovisualization approach. Journal of Environmental Planning and Management, 60(1), 115-134.

$\mathrm{Wu}$, J. S., \& Lee, J. J. (2015). Climate change games as tools for education and engagement. Nature Climate Change, 5(5), 413-418. 
Heintzman, R. (2020). Interactive Geovisualizations (iGEO): A New Approach to Teaching and...

\section{Biographical Statement}

Ryan HEINTZMAN is currently a Geography PhD student at Arizona State University. During his time as a graduate student, has worked on the development of course curriculum and lab textbooks for physical geography and climatology lab courses. His research focus areas are geography pedagogy and geography curriculum development, online learning, and complex topography and climate interactions. 